Wijeratne, S.D., Devapriya, K.A.K. and Gallage, S.D., 2021. Applicability of polymer building materials for productivity enhancement and cost reduction in Sri Lankan building industry. In: Sandanayake, Y.G., Gunatilake, S. and Waidyasekara, K.G.A.S. (eds). Proceedings of the $9^{\text {th }}$ World Construction Symposium, 9-10 July 2021, Sri Lanka. [Online]. pp. 110-121. DOI: https://doi.org/10.31705/WCS.2021.10. Available from: https://ciobwcs.com/papers/

\title{
APPLICABILITY OF POLYMER BUILDING MATERIALS FOR PRODUCTIVITY ENHANCEMENT AND COST REDUCTION IN SRI LANKAN BUILDING INDUSTRY
}

\author{
S.D. Wijeratne ${ }^{1}$, K.A.K. Devapriya ${ }^{2}$ and S.D. Gallage ${ }^{3}$
}

\begin{abstract}
Building construction contributes to a substantial consumption of raw materials compared to other sectors in Sri Lanka. Despite the excessive consumption of raw materials, industry is suffering due to low productivity and economic inefficiency. Thus, the circumstance has led to employ alternative building materials to overcome productivity and cost inefficiency with favourable impacts on sustainability. Polymer has become a global phenomenon with increasing demand as sustainable alternative. Polymer facilitates multiple applications in building construction due to its supreme properties and characteristics. Thus, this research focused develop a quantitative model based on factors related to productivity enhancement and cost reduction to measure the applicability of polymer materials in Sri Lankan building construction. A mixed approach consisting of semi structured interviews followed by a questionnaire survey was adapted for conduct this study. 12 experts were selected for the semi structured interviews and 34 respondents participated for the questionnaire survey. The significance of favourable impact to the productivity and cost efficiency of using polymer materials have been identified in the study. The study discussed the applicability of polymer types in building sector in Sri Lanka and derived resulted in a quantitative model to measure applicability of polymer adoption in the terms of productivity and cost related factors. Study concluded that inherent properties of polymers, buildability, ability to prefabricate, life cycle cost, handling would improve the applicability to local context. Further, relationship identified through the regression model would assist practitioners to select polymer materials while enabling researchers to improve the quality of the products.
\end{abstract}

Keywords: Alternative construction material; Cost reduction; Polymer; Productivity.

\section{INTRODUCTION}

The rapid increase of the population and complex needs of the people have complicated the nature of building constructions (Guribie and Tengan, 2019). As the industry faces multiple issues related to its outcome and the process, the productivity of the construction industry and cost reduction are receiving an increasing attention (Enshassi et al., 2013). Meanwhile, most traditional construction materials have caused significant amount of

\footnotetext{
${ }^{1}$ Department of Building Economics, University of Moratuwa, Sri Lanka, shashya95rcau@gmail.com

${ }^{2}$ Department of Building Economics, University of Moratuwa, Sri Lanka, University of Moratuwa,

Sri Lanka, kakdevapriya@uom.lk

${ }^{3}$ Department of Building Economics, University of Moratuwa, Sri Lanka, sasankag@ oom.lk
} 
environmental issues, health and safety issues, cost inefficiencies and productivity issues (Occupational and Environmental Health Department, 1999). On the contrary, the construction industry is considered to be one of the key industries with a significant influence over the economy (Bekdik, 2017). Therefore, there is no doubt that increasing the productivity of the construction industry and the materials being used will play a positive role in the overall economy.

In light of the above, Shinde and Hedaoo (2017) suggested that innovative practises would be ideal for improvement of construction productivity. The authors further claimed that introduction of polymer technology to the construction industry could reduce energy and raw material wastage while enhancing the quality of materials. Despite being limited to non-loadbearing applications such as mechanical, electrical and plumbing related systems during the initial stages of adoption (Masuelli, 2013; Headley, 2014), polymers are now being used in primary load bearing elements as well (Hughes et al., 2018). Halliwell (2010) claimed that reasons behind the rapid increase of use of polymer related materials can be the considerations the cost, quality and time related aspects.

Even though, most countries have extended their construction sector to incorporate polymer materials (Halliwell, 2010; Zhou et al., 2018), Sri Lankan construction industry has failed to move beyond the primary applications of polymers (Gunawardena et al., 2016). Further, most of the materials that can be used to produce polymer are being disposed as wastes causing environmental issues (Udagama and Kulatunge, 2014; Stone, 2019). Thus, it is very crucial to carry out an assessment of the applicability of polymer related materials in Sri Lankan building construction industry.

Therefore, this research attempts to analyse the applicability of polymer materials as alternatives for building construction in Sri Lanka. Initially the existing literature was critically reviewed to examine the polymer types and their characteristics that suitable for building construction in productivity and cost reduction perspective. Thereafter, interviews were conducted among experts to identify the motivators and challenges to use polymer building materials in building construction in Sri Lanka. Subsequently, a questionnaire survey was conducted based on gathered data develop a quantitative model based on factors related to productivity enhancement and cost reduction to measure the applicability of polymer materials in Sri Lankan building construction.

\section{LITERATURE REVIEW}

\subsection{Alternative Materials FOR BUILDing CONSTRUCTIONS}

The construction industry utilizes wider range of materials compared to others, mainly for the purposes of structural material, finishes, and services related materials (Ahmed and Sturges, 2015). Gama (2012) observed that global construction activities consume $40 \%$ of global energy and $30 \%$ of raw materials while being responsible for about $35 \%$ of carbon dioxide and $28 \%$ of landfill materials as construction waste. Hence, the dependency on traditional materials for construction, may not only be harmful for the environment but also for the economy as well (Sinha and Harison, 1995). Therefore, according to Gama (2012) the United Nations Commission has been promoting the importance of alternative building materials for human settlements since the early 1990s. On the other hand, polymer related alternatives provide the best solutions for addressing inefficiency, environmental issues, technological barriers, and cost effectiveness of the products (Correia, 2015). 


\subsection{POlymer Building MAterials AS An Alternative}

A polymer is a material usually composed of a hydrocarbon compound and has a wide range of applications and uses (Ruuska and Häkkinen, 2014). Polymer is basically produced by processing Carbon $(\mathrm{C})$ with Hydrogen $(\mathrm{H})$, Oxygen $(\mathrm{O})$, Nitrogen $(\mathrm{N})$ and other organic or inorganic elements (Calhoun and Peacock, 2006 ).

A composite material is a material made of two or more constituent materials having significantly different physical or chemical properties, when combined, produces a material having properties different from those of the respective components (Fazeli et $a l ., 2019)$. These polymer types have very different properties from each other and are therefore used in completely different applications. Polymers are materials with increasing consumption as engineering materials ranging from non-loadbearing applications to primary load bearing functions in the last several years (Koca, 2016; Hughes et al., 2018).

\subsection{Characteristics of Materials Affecting Productivity}

Despite being a prominent industry in most countries, the construction industry has suffered from decades of long unproductivity (Bekdik, 2017). According to the Organisation for Economic Co-operation and Development's (OECD) definition, 'productivity' is defined as a ratio between the output volume and the volume of inputs (OECD, 2019). Similarly, the U.S. Bureau of Labour Statistics defines productivity as a measure of economic performance that indicates how efficiently inputs are converted into outputs (Bekdik, 2017). Despite, the definitions and measures of productivity, it is a concept that is difficult to measure and is often defined by reference to the basic resources used and expressed as output from labour, machinery, or capital invested (Cheetham and Lewis, 2001).

Labour productivity is affected by several factors, but buildability is among the most important (Jarkas, 2010). Buildability is defined as the extent to which the design of a building facilitates ease of construction (Cheetham and Lewis, 2001). Furthermore, Poh and Chen (as cited in Jarkas, 2010), emphasized in an empirical study of 37 completed buildings concluded that designs with a high buildable score will result in more efficient usage of labour. So that it is understood that buildability has a high impact on productivity. The other factor which affects the productivity is the level of prefabrication (Jarkas, 2010). Prefabrication facilitates the effective use of inputs in the process of making outputs and results in less wastage, time consumption and better performance (Cheetham and Lewis, 2001). Therefore, it can be concluded that adopting materials which facilitates prefabrication in the construction tend to show higher productivity. The other considered factor for productivity is easiness of handling (Jarkas, 2010). If some materials are fragile or else hard to carry in operation so the labours take more time to perform a particular task (Bekdik, 2017). According to the facts described, it can be concluded that Buildability, Ability to Prefabricate, Handling easiness of materials contribute to the level of productivity in the construction projects.

\subsection{Characteristics of Materials AfFecting Cost Reduction}

Construction costs form part of the overall costs incurred during the development of a built asset such as a building (Kovacic and Zoller, 2015). Very broadly, construction costs are those costs incurred by the actual construction works themselves, and on some 
projects may be determined by the value of the contract with the contractor/builder. However, the construction contract may include costs that might not in themselves be considered literal construction costs (hard costs), such as fees, profits, overheads, and so on. There are some indirect factors which affect cost effectiveness (Cheetham and Lewis, 2001). According to Jarkas (2010), buildability factor also affect the construction cost. Author further described that with improved buildability not only excessive material wastage can be minimised but also labour hours can be effectively utilised. However, Heralova (2017) argued that considering only the construction cost in order to obtain sustainable design with economic optimization in the early design stages, is not enough. Further author described that in order to gain the maximum value for money, all costs incurred over the whole life span must be estimated. Furthermore, the types of material specified, the quality of the design and the contracting method have to be chosen directly upon operation and maintenance costs (Boussabaine and Kirkham, 2004). Thus, in material selection maintenance cost should be considered rather than the initial cost. Hence, Akgul and Giritli, (2015) and Koca (2016) suggested polymers as an alternative to many applications due to the durability and less maintenance cost.

According to the above findings the identified factors can be integrated to measure productivity enhancement and cost reduction in building construction. The factors are listed out with their impacts in Table 1.

Table 1: Factors to measure productivity enhancement and cost reduction

\begin{tabular}{ll}
\hline \multicolumn{1}{c}{ Factor } & \multicolumn{1}{c}{ Impact } \\
\hline Buildability & Productivity/cost reduction \\
Ability to prefabricate & Productivity \\
Reduction in LCC & Cost reduction \\
Handling easiness & Productivity/cost reduction \\
\hline
\end{tabular}

\subsection{THE IMPORTANCE OF StUdying THE USE OF Alternative MARTiALS IN BUILDING CONSTRUCTION}

The inefficiency and negative environmental impact of construction activities had led United Nations Commission to promote the importance of alternative building materials and it has further increased with concepts of sustainability (Gama, 2012; Heralova, 2017). Further, Shinde and Hedaoo (2017) and Zhou et al., (2018) believe that capability of polymers to produce strength-to-weight ratios, uplifted lifestyles and high-quality building features material would enable higher productivity by eliminating major challenges and barriers in construction while providing cost effective solutions.

With regard to the Sri Lankan context, Gunawardena et al. (2016) highlighted the potential of using innovative materials to produce better-performing buildings in Sri Lanka using non-traditional building systems (Gunawardena et al., 2016). Similarly, Udagama and Kulatunge (2014) criticized limited usage of polymer materials and the reluctance to create more quality and sustainable material in larger scale while having most of the recyclable materials disposed to landfills by the other industries. According to Gunawardena et al. (2016), in order to construct better performing buildings, the construction methods should be changed to innovative processes with alternative enhanced quality materials and equipment rather than conventional building systems. Even though, there are many global researches being carried on the adoption of polymers 
for construction there is a significant deficit with regard to the local context. Thus, it is very crucial to carry out an assessment of the applicability of polymer related materials in Sri Lankan building construction industry.

\section{METHODOLOGY}

The research concerns about the applicability of polymer material and its influence on productivity and cost reduction in Sri Lankan construction industry. Hence, in order to explore motivators and challenges with regard to the Sri Lankan context the qualitative research approach was initially selected as it allows to evaluated opinions regarding a certain phenomenon as explained by Gray (2004). However, the influence of polymer material on the productivity and cost reduction could not be explored due to the limited number of professional competent with both building construction and polymer materials. According to Cherry (2000), in such instances, qualitative approach would derive more subjective towards their respective field. Additionally, variables related to applicability based on productivity and cost reduction cannot be feasibly studied under a case study for this research as the dependent and independent variables cannot be organised as anticipated. Therefore, quantitative approach was selected to identify the influence on productivity and cost reduction as it allows to observe relationships between factors or scenarios as per Cherry (2000). Hence, the overall research approach was the mixed approach which is blend of quantitative and qualitative approach that is used simultaneously in the same study but in different stages.

\subsection{EXPERT INTERVIEWS}

Semi-structured interviews help collect data to understand and explore new ways of seeing a research topic (Cohen and Crabtree 2006). The interviewees, selected using purposive sampling to enable data saturation at the correct level, were all professionals. In selecting the interviewees, their availability for the interviews, willingness to take part in face-to-face interviews, and the ability to communicate (Etikan et al., 2016) were considered. Table 2 presents the details of the respondents.

Table 2: Summary of respondents for expert interviews

\begin{tabular}{lcc}
\hline \multicolumn{1}{c}{ Categories } & Government Sector & Private Sector \\
\hline Architects & 2 & 2 \\
Engineers & 2 & 2 \\
Quantity Surveyors & 2 & 2 \\
\hline
\end{tabular}

In addition to verifying the validity of the literature review findings, the interviewees indicated factors specific to government and private organizations. The collected data were manually analysed using directed content analysis because it reduces the volume of the data to be handled and facilitates the categorisation of the data by improving their contextual meaning as explained by Bengtsson (2016).

\subsection{QUESTIONNAIRE SURVEY}

A questionnaire survey was subsequently used to identify the of relationship applicability of polymer material based on productivity and cost reduction. According to Cherry (2000), quantitative data collected through questionnaire survey can be interpreted using statistical test for greater populations by considering a sample. Therefore, it allows to 
explore the relationship between the identified variables in a larger scale. However. When selecting participants for this study purposive sampling was used to select participants based on their knowledge, professional affiliations, working experience. From the 45 prospective participants, $40(88.89 \%)$ responded, however 6 were incomplete. Therefore, $34(75.56 \%)$ completed questionnaires were considered for the analysis. Table 3 presents the details of the respondents.

Table 3: Details of questionnaire survey respondents.

\begin{tabular}{llcc}
\hline \multicolumn{1}{c}{ Variable } & \multicolumn{1}{c}{ Categories } & Frequency & Percentage \\
\hline \multirow{2}{*}{ Sector } & Private & 23 & $67.65 \%$ \\
& Government & 11 & $32.35 \%$ \\
\multirow{3}{*}{ Area of Expertise } & Quantity Surveying & 12 & $35.29 \%$ \\
& Engineering & 13 & $38.24 \%$ \\
& Architecture & 9 & $26.47 \%$ \\
\multirow{3}{*}{ Work Experience } & 0 -5 years & 15 & $44.12 \%$ \\
& 5 - 10 years & 13 & $38.24 \%$ \\
& More than 10 years & 6 & $17.65 \%$ \\
\hline
\end{tabular}

Gathered data from questionnaire have been analysed in Statistical Package of Social Sciences statistical package (SPSS). Linear regression modelling has been used to identify the of relationship applicability of polymer material based on productivity and cost reduction. Furthermore, T- Test was carried out to evaluate the significance of issues for the implementation of polymer.

\section{DATA ANALYSIS}

\subsection{Applicability of Polymer Material to Productivity ENHANCEMENT AND COST REDUCTION}

To observe the influence on productivity enhancement and cost reduction, four vital factors were identified from the literature to be inquired through the interviews. Number of respondents who expressed positive responses are given in Table 4.

Table 4: Response for factors affecting productivity and cost reduction from interviews

\begin{tabular}{|c|c|c|c|c|c|c|}
\hline \multirow[b]{2}{*}{$\begin{array}{c}\text { Factors affecting productivity } \\
\text { and cost }\end{array}$} & \multicolumn{3}{|c|}{$\begin{array}{l}\text { Government } \\
\text { sector }\end{array}$} & \multicolumn{3}{|c|}{ Private Sector } \\
\hline & 兽 & 㞭 & 恶 & 总 & 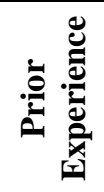 & 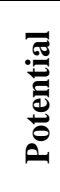 \\
\hline Buildability & 6 & 2 & 6 & 6 & 5 & 6 \\
\hline Ability to prefabricate & 6 & 3 & 6 & 6 & 5 & 6 \\
\hline Handling & 6 & 3 & 6 & 6 & 4 & 6 \\
\hline Reduction of LCC & 6 & 1 & 6 & 6 & 4 & 6 \\
\hline
\end{tabular}


Majority of the professionals from the private sector had used polymer material in their projects. Government professionals had limited exposure due government policies on use of alternative material. Respondents highlighted 'Buildability', 'Ability to prefabricate' and 'Handling' as prominent features of polymer composites which had led them to select such material over traditional material. The private sector respondents stated that both improvement of productivity and cost reductions had been observed with the use of polymer composites. The government sector respondents on the other hand, had observed prominent cost reduction over productivity increments given the limited applications of these materials. However, respondents unanimously agreed on the significant influence over cost reduction and productivity improvement compared to the traditional materials.

Figure 1 depicts the opinion on applicability of polymer application of the government and private sector professionals in different areas of expertise.

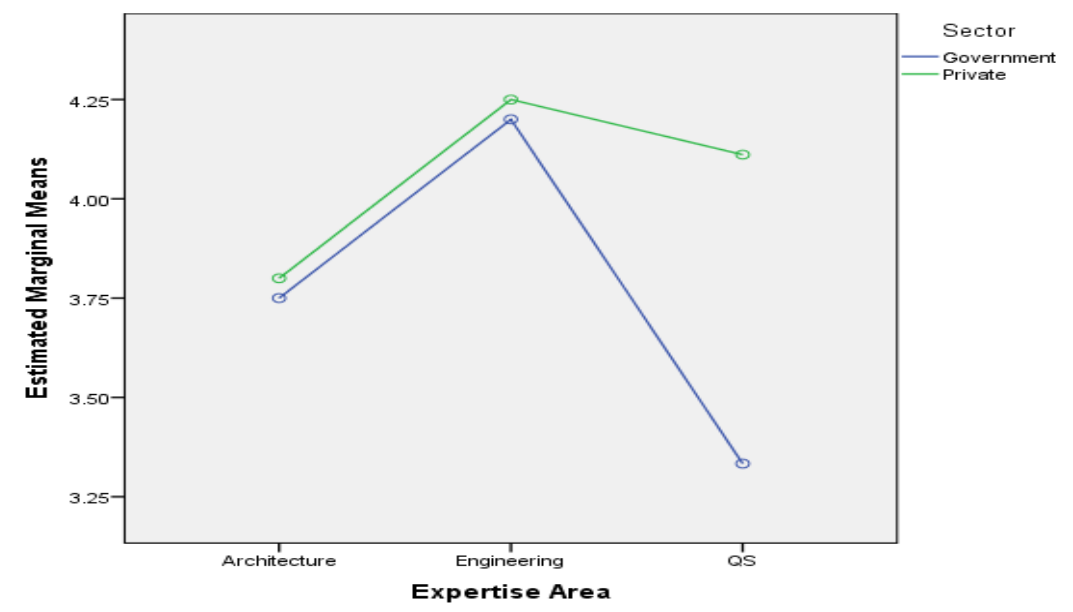

Figure 1: Means of opinion on applicability of polymer material

The government and private sector professional's opinion on applicability of polymer materials are further detailed in Table 5 can be assessed through the identified means of applicability.

Table 5: Summary of Two-way Anova test for applicability

\begin{tabular}{llcccc}
\hline \multirow{2}{*}{ Expertise Area } & \multirow{2}{*}{ Mean } & \multirow{2}{*}{$\mathbf{N}$} & \multicolumn{2}{c}{ 95\% Confidence Interval } \\
\hline \multirow{2}{*}{ Architecture } & Government & 3.750 & 4 & 3.096 & 4.404 \\
& Private & 3.800 & 5 & 3.215 & 4.385 \\
Engineering & Government & 4.200 & 5 & 3.615 & 4.785 \\
& Private & 4.250 & 8 & 3.788 & 4.712 \\
QS & Government & 3.333 & 3 & 2.579 & 4.088 \\
& Private & 4.111 & 9 & 3.675 & 4.547 \\
\hline
\end{tabular}

According to Figure 1 and Table 5, in all three areas of expertise private sector professional's level of applicability is higher as well as other two variables analysed previously. As discussed in previously, the sample size of government sector is not affected as it is the smallest size of sample. Since the private sector professionals have more awareness and usage, they have identified its applicability in Sri Lankan context 
rather than government sector. But compared to other two variables, this variable has slightly increased means. In the engineering professionals there is slight difference between two means. By considering the areas of expertise, QS professionals in government sector have the least mean, but vary from other two variables as QS professionals in private sector tend to show higher mean than architecture professionals in private sector. Thus, it is obvious that QS professionals' opinion on applicability is more significant than architecture professionals. Reasoning for this obtained results could be described as follows.

Applicability on polymer building materials based on factors that are directly affecting QS aspects. Buildability enhancement and therefore increase in productivity resulting reducing labour cost. Hence it is sufficiently affecting the QS aspects of cost, time. As cost mangers, they would like to manage their cost plans from cost overruns. But as architecture related professionals, they do not mainly concern on cost and technical aspect but the aesthetic view and value of designs. As the applications of polymer materials are not directly addressing architectural aspects, the means could lie on lower level according to their opinion. But with adopting different types of polymer related applications, this matter could be addressed.

\subsection{LINEAR REGRESSION MODEL}

To determine the relationship through regression modelling, a simple equation was formulated by using data collected from 34 professionals in the building sector. In this section, a relationship of factors affecting applicability were considered. The linear regression model was established with the aid of SPSS software tools and the sample of 34 professionals who responded were considered as input to the model. Figure 2 displays $\mathrm{R}$ and $\mathrm{R}$ Square values.

Model Summary

\begin{tabular}{l|r|r|r|l|}
\hline & & & \\
Model & $\mathrm{R}$ & $\mathrm{R}$ Square & $\begin{array}{c}\text { Adjusted R } \\
\text { Square }\end{array}$ & Std. Error of the Estimate \\
\hline 1 & $.836^{3}$ & .821 & .853 & .14452 \\
\hline
\end{tabular}

According to the model summary, R value equals to 0.836 , which means the relationship between these independent variables of factors and the dependent variable of applicability of polymer materials, has a positive and significant value. Significance of this value can be interpreted in accordance with correlation coefficient analysis. Hence, it is obvious that the strong positive relationship with these considered independent variables towards the dependent variable. Furthermore, R squared value of 0.821 can be interpreted as that $82.1 \%$ of the subjected dependent variable was derived from the considered four independent variables.

Figure 3 displays the coefficients of all the four variables and constant which derive the equation between independent and dependent variables. When considering the integrity and the accuracy of the formula, the significance ( $\mathrm{p}$-value) factor can be considered. It illustrates the influence of null hypothesis when the coefficient is zero. A low significance or $\mathrm{p}$ - value $(<0.05)$ indicates that the null hypothesis can be neglected as the low impact. 
As per the results, the constant has zero significance that explains a higher reliability of the value to the sample. All the variables consist of significances within the allowable level $(<0.05)$. In here, buildability factor has the highest positive relationship with applicability as denoted by the low p-value.

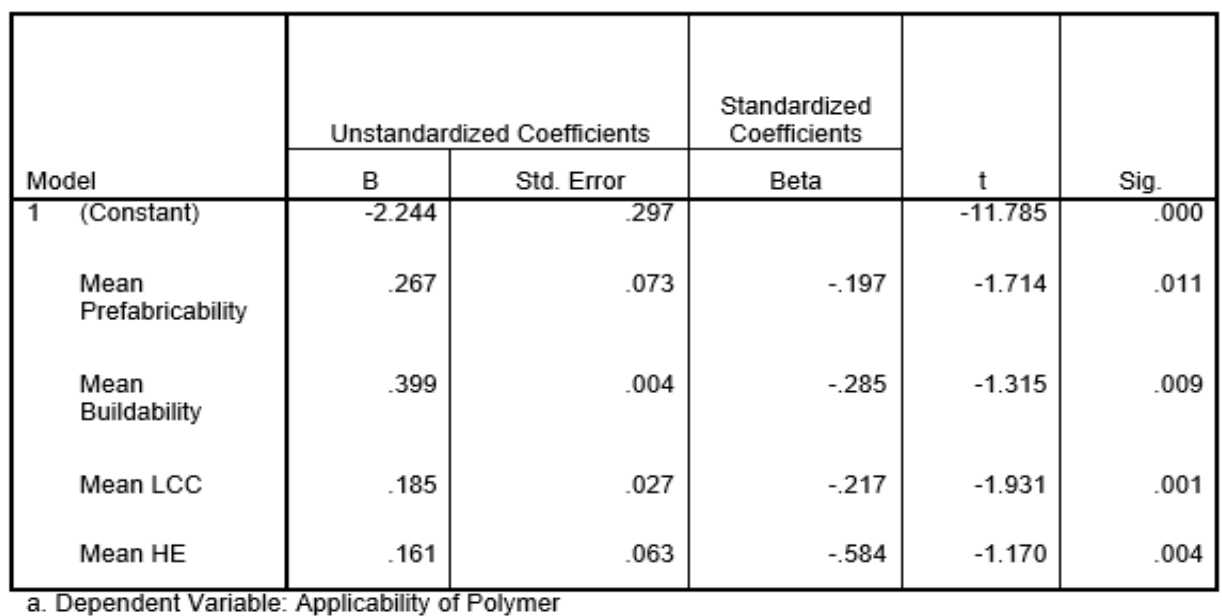

Figure 3: Coefficients of dependent variables for applicability

The computed formula on applicability of polymer material can be elaborated as follows.

$$
A p p=0.267(F 1)+0.399(F 2)+0.185(F 3)+0.161(F 4)-2.244
$$

Where, App = Applicability, F1 = Ability to prefabricate, F2 = Buildability, F3 = Life Cycle Cost and F4 = Handling

All above factors share positive relationships with the apllicability of polymers to the construction industry of Sri Lanka. Eventhough a small sample was selected due to limited number of professionals competent in both polymer technology and building sector in Sri Lanka, model has obtained significant figures that determines the huge impact of considered variables. Hence literature findings of these four factors which affect to applicability are significantly validated through this model.

\section{DISCUSSION}

Overall findings of this research suggest that, factors affecting productivity and cost reduction of material which were identified from the literature review are apllicable for polymer materials in Sri Lankan context as well. Buildability of polymers obtained the highest coefficient denoting highest influence on apllicability. The findings revealed that ability of molymer materials to be moulded into various shapes and sized with their mechanical properties helps to enhance the buildability acknowleding the findings of Koca (2016). Polymers may help to increase buildability by providing various sizes and shapes which can reach the intended places. Similarly, polymer's degree of prefabrication was also revealed to have a significant influence on improving productivity. is comparatively higher than other materials. Polymers with different shapes and sizes may encourage and improve off site fabrications which may lead to reduce construction waste similar to findings of Shinde and Hedaoo (2017). Moreover, admixture, curing agents can be also considered as examples where polymers enhancing the productivity while determining the utmost performance of the structure. Handling of polymer alternatives was identified with the least influence for the applicability of polymer material to the Sri 
Lankan context. Most of the polymer applications are light weight but provide higher tensile strength therefore significantly contribute to the similar to the findings of Bekdik (2017). Not only the permanent works, but also the temporary works related to the building construction also affect the productivity. Thus, rather than using conventional formworks such as timber, glass reinforced plastic can be used.

Low lifecycle costs were also found to be a significant factor for the apllicability of ploymer materials to the Sri Lankan context. Therefore, as identified by Koca (2016) low cost and durablity of material have a signifannt influence on LLC, thereby, polymers are materials in general compared to other conventional materials. Most of the polymers are less expensive than other alternatives and less weight, easy handling in operations thus less cost in transporting handling cost. As most of the polymer types have wide range of production forms wastage is minimised.

The regression model identified the potential of Buildability and Ability to prefabricate to improve productivity and cost efficiency. Prefabrication and buildability of polymer composites facilitates the effective use of inputs in the process of making outputs and results in less wastage, time consumption and better performance as identified by Cheetham and Lewis (2001). Furthermore, the fidnings confirmed that the more easiness of handling the materials results in a higher productivity similar to the findings of Jarkas (2010). As per the findings from both interviews and questionnaire surveys, the durability and less maintenance cost, make polymers ideal for many applications as highlighted by Akgul and Giritli (2015). Regression analysis revealed that, all above factors share positive relationships with the apllicability of polymers to the construction industry of Sri Lanka.

\section{CONCLUSIONS AND RECOMMENDATIONS}

The study primarily focused on developing a quantitative model based on factors related to productivity enhancement and cost reduction to measure the applicability of polymer materials in Sri Lankan building construction. The collected data through 34 respondents who work in building industry as different areas of expertise have been used to build a regression model as quantitative measure of applicability of polymer materials in Sri Lankan building sector. The model has been supported by many other different statistical tools to check the reliability and the consistency of the ultimate outcome. Scale reliability test was carried out to check the internal consistency of the data set obtained from 34 professionals. Variable computation was carried out to measure statistical measures of central tendency and dispersion. The obtained significance values were within the allowable level. The level of integrity was clearly visualised with very low standard errors of all factors resulted in the model. Further, model was elaborated as an equation to measure the applicability of polymer materials in Sri Lankan building construction. As observed throughout the study, polymers are highly useful in achieving productivity and cost concerns. Thus, recommendations can be extended to adopt polymer materials in designing and developing specifications to achieve less wastage, high durability, and less time consumption in the process. Further, relationship identified through the regression model would assist practitioners to select polymer materials while enabling researchers to improve the quality of the products. 


\section{REFERENCES}

Ahmed , A., and Sturges, J., 2015. Materials science in construction: an introduction. New York, USA: Routledge Ltd.

Akgul, S., and Giritli, H. 2015. Research trend of sustainability in construction journals. In: Charles Egbu (ed.) CIB International Conference Proceedings, London 23-25 November 2015. London: London South Bank University, pp. 141-151.

Bekdik, B., 2017. Improving productivity in building construction by repetitions in products, processes, and organisations. Lyngby, Denmark: University of Denmark

Bengtsson, M. 2016. How to plan and perform a qualitative study using content analysis. NursingPlus Open, 2, pp. 8-14.

Boussabaine, A., and Kirkham, R. 2004. Whole life-cycle costing, risk and risk responses. Oxford, UK: Blackwell Publishing Ltd.

Calhoun, A., and Peacock, A., 2006 . Polymer Chemistry: Properties and Applications. Cincinnati: Hanser Gardner Publications

Cheetham, D., and Lewis, J. 2001. Productivity, buildability and constructability: is work study the missing link? In: Akintoye, A (ed.), $17^{\text {th }}$ Annual ARCOM Conference, Sheffield 5-7 September 2001. 1, pp. 271280. Salford: University of Salford, pp. 271-280

Cherry, A.L. 2000. A research primer for the helping professions: methods, statistics and writing. Belmont: CA: Brooks / Cole.

Cohen, D. and Crabtree, B. 2006. Qualitative research guidelines project [Online]. Princeton, Robert Wood Johnson Foundation. Available from: http://www.qualres.org/HomeQual-3512.html [Accessed 24 April 2021].

Correia, D., 2015. Polymers in building and construction. In Gonçalves, M., and Margarido, F., Materials for Construction and Civil Engineering. New York: Springer.

Enshassi, A., Kochendoerfer, B. and Abed, K., 2013. Trends in productivity improvement in construction projects in Palestine. Revista Ingeniería de Construcción RIC, 28(2), pp. 173-206.

Etikan, I., Musa, S.A, and Alkassim, R.S. 2016. Comparison of convenience sampling and purposive sampling. American Journal of Theoretical and Applied Statistics, 5(1), pp. 1-4.

Fazeli, M., Florez, J., and Simao, R., 2019. Improvement in adhesion of cellulose fibers to the thermoplastic starch matrix by plasma treatment modification. Composites Part B: Engineering, 163, pp. 207-216.

Gama, M., 2012. The use of Alternative building materials in developing countries: Addressing challenges faced by stakeholders. In: World Construction Conference 2012 - Global Challenges in Construction Industry, Colombo 28-30 June 2012. Colombo: CIOB. pp. 266-275.

Gray, D.E. 2004. Doing Research in the Real World. London: Sage Publications.

Gunawardena, T., Karunaratne, R., Mendis, P., and Ngo, T., 2016. Prefabricated construction technologies for the future of Sri Lanka's construction industry. In: The $7^{\text {th }}$ International Conference on Sustainable Built Environment. Kandy 16-18 December 2016. Kandy: University of Peradeniya. pp. 16-18.

Guribie, F., and Tengan, C. 2019. A proposed knowledge management implementation framework for the Ghanaian construction industry. Journal of Building Construction and Planning Research, 7(1). pp. 110 .

Halliwell, S., 2010. Polymers in building and construction. Shropshire, UK: Rapra Technology Limited.

Headley, M., 2014. EVA finds popularity among decorative fabricators. News Analysis:Trends US Glass, 6(4). pp. $1-5$

Heralova, R.S., 2017. Life cycle costing as an important contribution to feasibility study in construction projects. Procedia Engineering, 196, pp. 565-570.

Hughes, R., Drinkwater, B., and Smith, R., 2018. Characterisation of carbon fibre-reinforced polymer composites through radon-transform analysis of complex eddy-current data. Composites Part B: Engineering, 148, pp. 252-259.

Jarkas, A.M., 2010. Analysis and measurement of buildability factors affecting edge formwork labour productivity . Journal of Engineering Science and Technology Review, 3(1), pp. 142-150. 
Koca, G., 2016. Interior finishing materials. In Efe, R., Matchavariani, L., Yaldir, A. and Levai L. (eds.). Developments in Science and Engineering. Bulgaria: St. Kliment Ohridski University Press.

Kovacic, I., and Zoller, V. 2015. Building life cycle optimization tools for early design phases. Energy, 92(3), pp. 409-419.

Masuelli, A., 2013. Fiber reinforced polymers. Argentina: San Luice.

Occupational and Environmental Health Department., 1999. Hazard prevention and control in the work environment: Airborne dust. Geneva: Occupational and Environmental Health Department

OECD 2019. Towards improved and comparable productivity statistics, OECD Library, Paris, [Online] Available from: https://www.oecd.org/sdd/productivity-stats/ [Accessed 20 April 2021].

Ruuska, A., and Häkkinen, T. 2014. Material efficiency of building construction. Buildings, 4(3), pp. 266294.

Shinde, V.J., and Hedaoo , M.N., 2017. A review on productivity improvement in construction industry. International Research Journal of Engineering and Technology, 4(11), pp. 210-215.

Sinha, P., and Harison, S., 1995. A study of alternative building materials and technologies for housing in Bangalore, India. Construction and Building Materials, 9(4), pp. 211-217.

Stone, E., 2019. About plastic pollution in Sri Lanka. Islington, Waste-Trading. Available from: https://waste-trading.com/index.php/upcoming-events-in-the-industry/12-english/sections/188-srilanka [Accessed 20 April 2021].

Udagama, U., and Kulatunge, A., 2014. Development of Sustainable Roofing Material from Waste. International Conference of Sustainable Built Environment. 2014, pp. 1-6

Zhou, C., Li, Y., Jin, X., He, Y., Xiao, C. and Wang, W., 2018. Highly hydrophobic conductive polyester fabric based on homogeneous coating surface treatment. Polymer-Plastics Technology and Engineering, 58(3), pp. 246-254. 